\title{
IMPROVING THE EFFICIENCY OF THE THREE-STAGE TECHNIQUE OF MATHEMATICAL MODEL IDENTIFICATION OF COMPLEX THERMAL POWER EQUIPMENT
}

\author{
Vitalii Alekseiuk ${ }^{1 *}$ \\ ${ }^{1}$ Melentiev Energy Systems Institute of Siberian Branch of the Russian Academy of Sciences, Irkutsk, Russia
}

\begin{abstract}
The problems of state estimation of thermal power system operation and identification of mathematical model parameters have not been acceptably solved due to the complexity of studied objects and their mathematical models, and the lack of effective methods, algorithms and computer programs to solve the required mathematical problems. The results of solving the indicated problems are of importance as such, and play a great part in the qualitative solution to the problems of thermal power equipment control, e.g., the problems of optimal load dispatch among thermal power plant units and optimal control of thermal power equipment operation conditions. The paper describes an effective three-stage technique of mathematical model identification of complex thermal power equipment. The technique allows us to more effectively detect gross errors in measurements of control parameters used for identification of the mathematical model of the studied equipment, to evaluate correctness and rectify errors in the mathematical model construction, and to improve identification accuracy. The article presents a new formulation of the optimization problem for more efficient identification of mathematical models of heat power equipment. An effective three-stage technique of mathematical model identification of complex thermal power equipment was tested on a detailed mathematical model of the present-day $225 \mathrm{MW}$ generating unit that was constructed by the author. The paper presents results of solving the identification problem of mathematical model parameters of a generating unit.
\end{abstract}

Keywords: formulation of the optimization problem, identification of parameters, mathematical modeling, accuracy criterion, measured control parameters, model adjustment, relative discrepancies, operation conditions, state estimation, coal-fired generating unit.

Financing: The research was carried out under State Assignment, Project 17.1.1 (reg. no. AAAA-A17117030310433-6) of the Fundamental Research of Siberian Branch of the Russian Academy of Sciences.

\section{Introduction}

Thermal power plants (TPPs) and combined heat and power plants (CHPPs) operating on fired fuels continue to form the basis of the electric power industry in the Russian Federation, especially in the regions of the Urals and Siberia. According to research, more than $60 \%$ of the total electricity generation in Russia falls on TPPs and power plants of industrial enterprises [1,2]. A similar picture is observed in the distribution of the installed capacity of power plants of the UES of Russia - more than $65 \%$ is accounted for by TPP units. Moreover, the BP Statistical Review of World Energy confirms the trend of widespread use of fossil fuels (especially coal) to generate electricity and heat at TPPs around the world [3]. According to some forecasts, despite the increasing role of renewable energy sources, the growth of coal fuel consumption is expected in the coming decades $[4,5]$. Thus, fossil coal and other types of fossil fuels are the main source of energy in Russia and the world.
Consequently, the tasks of increasing the energy and economic efficiency of the operation of the main equipment of TPPs operating on fired fuel are among the most urgent and deserving of attention.

The present-day thermal power units such as coalfired generating units and their boiler units, steam turbines and other auxiliary equipment are technical systems with highly complicated flow diagrams, diverse elementary composition and operation conditions. Therefore, the methods of mathematical modeling and optimization of schemes and parameters are the main tools to study thermal power equipment at TPPs. It should also be noted that the mathematical models developed for the existing heat and power equipment must be properly tuned (identified) for the real operating modes of this equipment and with sufficient accuracy to reflect the real processes taking place in it. Consequently, the task of identifying (or adjusting) mathematical models of TPP should be performed in conjunction with optimization calculations and

Corresponding author: alexeyuk.vitaliy@yandex.ru 
assessment of the state of the heat and power plants under study.

It is important to note that the significant complexity of the mathematical models of modern TPP and the need to adjust them to the actual state changing over time creates serious obstacles in their optimization studies. Because of this, the methods of mathematical modeling and optimization are not widely used in the research and operation of complex heat and power equipment. The insufficiently extensive application of the effective methods of mathematical modeling, in general and their use to control operation conditions of TPPs, in particular are explained by some difficulties, such as significant complexity of mathematical models of current TPUs and need to adjust these models to the real equipment state changing in the course of time.

Thus, in practice the problems of thermal power system state estimation and identification of mathematical model parameters have no feasible solution due to the complexity of the studied objects and their mathematical models, and the lack of effective methods, algorithms and computer programs to solve the required mathematical problems. The results of solving the indicated problems are important as such and play an essential role for the qualitative solution of TPU control problems, e.g., for the optimal load dispatch among TPP units and the optimal control of operation conditions of TPUs and TPPs.

The Department of Thermal Power Systems at Melentiev Energy Systems Institute has gained rich experience in the study of complex thermal power units and thermal power plants. The works by A.M. Kler and N.P. Dekanova are among the early works that focus on approaches to optimization of mathematical models of thermal power units at real-time control of operation conditions of CHPPs [6-9]. A coordinated technique for the studied equipment diagnostics that is based on the joint solution of extremum optimization problems of state estimation and identification of characteristics of TPUs was proposed by A.V. Mikheev [10]. Moreover, an approach to the improvement of initial information quality by elimination of errors in the bad metered parameters is suggested in the work [11]. The studies by A.M. Kler, A.S. Maximov and E.L. Stepanova [12-15] are among the latest works devoted to this topic. They focus on development of "high-speed" mathematical models of main equipment at TPPs to perform complex optimization calculations of operation conditions of CHPPs, and also describe a technique for adjustment of mathematical models to a real state of the studied equipment. The technique allows the adjustment of mathematical model coefficients so that the obtained results correspond most accurately to the real equipment state, which validates optimization solutions.

In addition, the following works on this topic can be distinguished. The study [16] provides an approach based on multimodal optimization (calculations in various modes of equipment operation) as a basis for calibrating a mathematical model. The methodology is based on a genetic algorithm and is dedicated to the tuning of dynamic nonlinear systems such as biological growth models and effective management models to increase profits. The work [17] investigates the problem of detecting and diagnosing malfunctions of industrial equipment using the example of a power plant. Another study [18] describes a method of operational control over the performance of a steam turbine, based on a more accurate measurement of coolant flows and a developed method of matching the obtained data.

In previous works, the authors proposed to apply a new integrated approach when adjusting mathematical models of existing heat and power equipment to its real state based on the results of measurements of control parameters. Articles [19-21] described an improved method for identifying the parameters of mathematical models of thermal power equipment of TPPs, which is based on the idea of dividing a complex initial optimization problem into three simpler problems in order to improve the solution accuracy and convergence of the optimization process. The articles [22,23] consider an approach to assessing the achieved accuracy of tuning mathematical models and calculating the effect of changing the operating mode of a thermal power plant on the efficiency of its model elements.

This paper describes an effective three-stage technique for identifying mathematical models of complex heat and power equipment, which allows to achieve high accuracy of tuning the TPP models to its actual state. For the first time, the original objective function of the third stage of identification, developed by the authors, is presented, which significantly increases the accuracy of solving the identification problem.

\section{Description of the three-stage technique of mathematical model identification of complex thermal power equipment}

At the first stage of the identification problem solution the incorrect measurements of control parameters are revealed and eliminated from further calculations. The incorrect measurements are the values of the metered parameters that exceed the declared accuracy of sensors used in the tests. Such measurements can be detected by solving the minimization problem of the auxiliary coefficient $\psi$ for each individual operation condition of equipment. The coefficient $\psi$ corresponds to the value of the maximum relative deviation among all the metered parameters.

The mathematical model parameters of the identification problem can be divided conventionally as follows: the parameters of $x_{m}$ that are metered on the studied unit and are the input information for the mathematical model; the metered parameters of $y_{m}$ that are the output information for the mathematical and the parameters of $x_{u m}$ that are not metered on the real unit and are the input information for the model. The array of the adjustable coefficients $\theta$ of the mathematical model is selected for each model individually. They are intended to influence physical processes occurring in the mathematical model elements. Usually such parameters comprise coefficients of thermal efficiency of boiler heat transfer surfaces, hydraulic resistances of heat 
exchangers, internal relative coefficients of turbine compartments and others. To identify the adjustable coefficients of the model, measurements of temperature, pressure, flow rate and power are used at various points of the technological scheme of the TPP in several steady-state operation modes. In addition, sensor accuracy values are required and are used to obtain appropriate control measurements.

It is important to note that at the first stage of identification, the values of the tunable coefficients of the mathematical model are often unknown. In this regard, it is proposed to use one of two approaches. Firstly, you can use the previous values of the coefficients if the identification was carried out earlier or there are values of the coefficients of a similar installation. Secondly, it is allowed to set approximate values of the coefficients, taking into account the physical condition of the TPP elements and other known features of the installation under study. The array of adjustable coefficients is not included in the optimized parameters of the problem being solved for the first stage of identification. The mathematical statement of the first identification stage is the following.

$$
\begin{aligned}
& \min \psi \\
& x_{m}, X_{u m}, \psi \\
& H\left(y_{m}, x_{m}, x_{u m}, \theta\right)=0 \\
& G\left(y_{m}, x_{m}, x_{u m}, \theta\right) \geq 0 \\
& x_{m j}-\psi \cdot \sigma_{x j} \leq \overline{x_{m j}} \leq x_{m j}+\psi \cdot \sigma_{x j} \\
& y_{m k}-\psi \cdot \sigma_{y k} \leq y_{m k} \leq y_{m k}+\psi \cdot \sigma_{y k} \\
& \sigma_{x}=\left(S_{x} \cdot \alpha_{x}\right) / 3 \\
& \sigma_{y}=\left(S_{y} \cdot \alpha_{y}\right) / 3
\end{aligned}
$$

where $H$ is the function of equality constraints that includes all equations of the mathematical model and its elements (equations of heat transfer, heat balance and others); $G$ is the function of inequality constraints that includes physical and operating constraints on real equipment operation; $\psi$ is the coefficient equal to the absolute maximum relative deviation of parameters (the parameters calculated by the mathematical model are with the upper bar, the parameters obtained by measurements on the real equipment - without the bar); $\sigma_{x}, \sigma_{y}$ are the measurement error variances of the vectors $x_{m}$ and $y_{m}$, respectively, $S$ is the upper limit of the sensor measurement; $\alpha$ is the class of sensor precision.

To determine erroneous measurements, it is needed to reveal active constraints on the deviation of the parameter metered on the unit from the parameter calculated on the mathematical model. The measurement value in this constraint can be treated as erroneous and excluded from further consideration. The abovedescribed cycle of calculations must be performed for each of the considered operating modes. Usually choose from three to five steady-state operating modes of TPP with different load. It is important that these modes are in one relatively small-time interval in order to consider the adjustable coefficients of the mathematical model constant. The calculations have showed that such an approach makes it possible to more effectively detect measurement errors and minimizes redistribution of erroneous measurements among the parameters in different operation conditions.

It is noteworthy that the calculations at this stage are not always possible. This concerns thermal power units with an insufficient number of sensors and hence, insufficient amount of initial information for identification for an individual condition. If the number of measurements is approximately the same or exceeds the number of adjustable coefficients, the calculations at this identification stage are possible. Otherwise, the second identification stage that is performed for several conditions concurrently is necessary. In such a case the number of control parameter measurements will be satisfactory to successfully solve the stated problem.

At the second stage of the identification problem solution the mathematical model of the studied equipment is tested for availability of modeling errors and elimination of remaining gross errors in measurements.

The statement of the optimization problem is similar to the problem solved at the first stage, except that it is solved for all considered conditions concurrently (as evidenced by the index $i$ indicating the sequence number of equipment operation condition). The problem is formulated as follows.

$$
\min _{\substack{X_{m}^{\prime}, X_{u m}^{\prime}, \theta, \psi \\ n_{n,}}} \psi
$$

subject to

$$
\begin{gathered}
H\left(y_{m}^{i}, x_{m}^{i}, x_{u m}^{i}, \theta\right)=0 ; \\
G\left(y_{m}^{i}, x_{m}^{i}, \overline{x_{u m}^{i}}, \theta\right) \geq 0 ; \\
x_{m j}^{i}-\psi \cdot \sigma_{x j} \leq \overline{x_{m j}^{i}} \leq x_{m j}^{i}+\psi \cdot \sigma_{x j} ; \\
y_{m k}^{i}-\psi \cdot \sigma_{y k} \leq \overline{y_{m k}^{i}} \leq y_{m k}^{i}+\psi \cdot \sigma_{y k} \\
\sigma_{x}=\left(S_{x} \cdot \alpha_{x}\right) / 3 \\
\sigma_{y}=\left(S_{y} \cdot \alpha_{y}\right) / 3
\end{gathered}
$$

The calculations have showed that the solution to this problem allows the incorrect description of processes occurring in TPUs by the mathematical model to be detected. If the solution yields the parameters with a significant deviation of measurements in different equipment operation conditions, then it points to the lack of the required coefficient in the list of adjustable ones or the inaccurate construction of the mathematical model. Besides, the minor heat carrier flows that are neglected in the mathematical model construction for the studied equipment can cause an additional error in identification. Therefore, at this stage of calculations it is possible to make required changes in the model structure describing 
specific features of the studied thermal power equipment.

The use of the so called "three-sigma" rule in this study is explained by the fact that the probability belief in this case equals 0.997 [24]. Therefore, it is possible to reasonably argue that all possible random errors in measurements with the normal distribution do not practically exceed 3 sigma in the absolute value. In equations $(4,5,11,12)$ the minimized auxiliary coefficient $\psi$ specified initially by the large numbers 60 100 is used instead of the multiplier equal to 3.0. This substitution is necessary for considering the errors of the applied sensors and the imperfection of the calculation technique, as well as the errors in mathematical models. In the process of the optimization calculation $(1,8)$ this coefficient tends toward the value 3.0 , but in practice it often takes somewhat lower value.

If the measurements with gross measurement errors were successfully eliminated and the mathematical model correctly calculates the processes occurring in the installation elements, then the value of the coefficient $\psi$ will take on a value equal to or less than 3.0. This will mean that all existing relative discrepancies of control parameters can be explained by the error of the sensors used to obtain the corresponding measurements. As a result of the optimization calculation, it is possible to obtain the value of the coefficient $\psi$ greater than the value equal to 3.0. In this case, it is possible to estimate the value of the additional error that is introduced into the calculation result due to the imperfection of the mathematical model of the installation. It is proposed to consider that the error equal to $\delta=\psi-3$ characterizes the additional error of the mathematical model of the heat power equipment under study and the methods of its calculation. Thus, the suggested technique makes it possible to evaluate an additional error caused by the imperfection of the standard calculation methods and simplifications included in the mathematical model.

At the third stage of identification, the final optimization calculation is performed, which makes it possible to increase the accuracy of tuning the mathematical model. The third identification stage aims to achieve the maximum possible closeness between the real equipment operation and the calculations on the mathematical model.

In the previous works of the authors, the sum of the squares of the relative residuals of the control parameters in all considered modes of operation of the TPP was used as the objective function of the third stage of identification. The optimization problem, being solved at this stage, had the following form (the conditions of the problem are similar to those at the second stage of identification).

$$
f=\sum_{i=1}^{R}\left[\sum_{j=1}^{N} \frac{\left(x_{m j}^{i}-\overline{x_{m j}^{i}}\right)^{2}}{\sigma_{x j}^{2}}+\sum_{k=1}^{M} \frac{\left(y_{m k}^{i}-\overline{y_{m k}^{i}}\right)^{2}}{\sigma_{y k}^{2}}\right]
$$

where $R$ is the number of calculated operation conditions; $N$ is the dimension of the vectors $x_{m} ; M$ is the dimension of the vectors $y_{m}$.
In this paper, for the first time, the new formulation of the optimization problem of the third stage of identification is proposed, which will significantly increase the accuracy of the solution and further improve the convergence of the optimization process. The new objective function is the sum of individual coefficients $\psi_{j}, \psi_{k}$ (instead of a single coefficient in all equations of constraints), which are factors in the equations of constraints of the inequalities of the optimization problem. Therefore, minimizing the sum of these individual coefficients will lead to a decrease in the total residual and an increase in the accuracy of tuning the mathematical model to the actual state of the equipment under study. Taking into account the above-stated original approach, the mathematical problem of the third stage of identification has the following form.

$$
\min _{x_{n}^{i}, x_{s}^{i}, \theta, \psi_{j}, \psi_{k}} \sum_{l=1}^{R}\left[\sum_{j=1}^{N} \psi_{j}^{i}+\sum_{k=1}^{M} \psi_{k}^{i}\right]
$$

subject to:

$$
\begin{gathered}
H\left(y_{m}^{i}, x_{m}^{i}, x_{u m}^{i}, \theta\right)=0 \\
G\left(y_{m}^{i}, x_{m}^{i}, \overline{x_{u m}^{i}}, \theta\right) \geq 0 \\
x_{m j}^{i}-\psi_{j}^{i} \cdot \sigma_{x j} \leq \overline{x_{m j}^{i}} \leq x_{m j}^{i}+\psi_{j}^{i} \cdot \sigma_{x j} \\
y_{m k}^{i}-\psi_{k}^{i} \cdot \sigma_{y k} \leq \overline{y_{m k}^{i}} \leq y_{m k}^{i}+\psi_{k}^{i} \cdot \sigma_{y k} \\
\sigma_{x}=\left(S_{x} \cdot \alpha_{x}\right) / 3 \\
\sigma_{y}=\left(S_{y} \cdot \alpha_{y}\right) / 3
\end{gathered}
$$

It is necessary to note several significant and fundamental differences of the new approach proposed by the authors to the formulation of the optimization problem at the third stage of identification. First, the objective function itself (16) has been significantly revised itself, which takes on a simpler and more logical form, consisting only of mathematical addition operators, in contrast to the already existing function (15). Second, the composition of the optimized parameters of the optimization problem is replenished, including the arrays of individual coefficients $\psi_{j}, \psi_{k}$. At first glance, the proposed new approach will negatively affect the speed of solving the problem, since the dimension of the optimization problem increases somewhat. On the other hand, it is necessary to take into account the better convergence of the new objective function and its greater simplicity for calculation and better convergence of the optimization process.

After identification termination, the values of the adjustable coefficients $\theta$ of the mathematical model are fixed and not subject to further changes, and the mathematical model is considered adjusted to the real equipment state. Note that all identification stages are solved strictly in sequence and take into account changes in the mathematical model that are made at the previous stages.

The described technique allows assessing the identification of mathematical model parameters of the 
studied thermal power equipment. The absolute relative discrepancies of control parameters ( $x$ is the input information for the model, $y$ is the output information) are taken as the criterion. The discrepancies are calculated by the formulas:

$$
\begin{aligned}
k_{x} & =\left|x_{m}-\overline{x_{m}}\right| / \sigma_{x} \\
k_{y} & =\left|y_{m}-\overline{y_{m}}\right| / \sigma_{y}
\end{aligned}
$$

The overall accuracy of the identification problem solution can be obtained by calculation of the sum of the absolute relative discrepancies in control parameters in all considered operation conditions by the formula.

$$
k_{i d}=\sum_{l=1}^{R}\left[\sum_{j=1}^{N} \frac{\left|x_{m j}^{i}-\overline{x_{m j}^{i}}\right|}{\sigma_{x j}}+\sum_{k=1}^{M} \frac{\left|y_{m k}^{i}-\overline{y_{m k}^{i}}\right|}{\sigma_{y k}}\right]
$$

where $R$ is the number of calculated conditions; $N$ is the dimension of the vectors $x_{m} ; M$ is the dimension of the vectors $y_{m}$.

\section{Results of identification of mathematical model parameters for the studied generating unit}

In this study the present-day generating unit installed at the Kharanor condensing power plant (Yasnogorsk settlement, Trans-Baikal Territory) was taken as a prototype for the mathematical model. It consisted of a 225 MW steam turbine unit K-225-12,8-3P and a high pressure reheat boiler unit ЕП-630-13,8-565 БТ with a rating of $630 \mathrm{t} / \mathrm{h}$. The flow diagrams and the mathematical models of the turbine and boiler units are described in greater detail in the papers $[25,26]$.

The mathematical model of a generating unit was constructed by the author using the software "System of computer-based construction of programs" developed at Melentiev Energy Systems Institute of SB RAS [27]. The calculation scheme of the generating unit comprises 100 elements and 169 ties between them. The obtained mathematical model contains 1017 input parameters, 1455 output parameters, 54 parameters of which are calculated iteratively and should be set with an initial approximation.

The calculation results obtained with the help of the improved technique developed by the author for identification of mathematical model parameters of thermal power equipment are given with respect to the described generating unit. The values of the metered parameters at the scheme control points that are necessary for identification of mathematical model parameters were taken from the sensor readings given by the engineering personnel of the power plant. The accuracy class of the applied sensors are: for the sensors metering electric load $-1 \%$, pressure $-1.5 \%$, water and steam temperature $-2 \%$, flow rate $-3 \%$, gas temperature $-5 \%$.
The calculations were made for three selected operation conditions of the generating unit (the minimum load $125 \mathrm{MW}$, the load $227 \mathrm{MW}$ and the maximum load $235 \mathrm{MW}$ ), each containing 60 metered parameter values at different flow diagram points, of which 5 metered parameters are the input (preset) information for the mathematical model and 55 parameters are the output (calculated) information for the mathematical model.

The calculations carried out at the first stage of identification for each of the 3 considered operating modes separately, revealed some ambiguous measurements. The engineering analysis of these measurements indicated the presence of a gross measurement error, so their values were excluded from the optimization problem.

With regard to the considered power unit, the calculations performed at the second stage of identification allowed minimizing the objective function (8) to a value of 3.104. As mentioned above, an error of 3.0 or less can be attributed to the stated accuracy of the sensors used to obtain the measurements. An additional error, equal in this case to 0.104 , can be explained by the imperfection of the normative methods for calculating the boiler unit and the turbine unit, as well as the necessary assumptions in the mathematical model of the power unit. The value of the accuracy criterion (25) was 231.88 .

To obtain the final values of the adjustable coefficients of the model, optimization calculations of the third stage of identification of the mathematical model of the power unit were performed. The upper limit of the optimized individual coefficients $\psi_{j}, \psi_{k}$ was fixed at 3.20. Calculations were carried out for both the existing objective function (15) and the new function (16). The values of the identification accuracy criterion were 189.18 and 159.02 , respectively.

Thus, there is an advantage of the new formulation of the optimization problem, the accuracy criterion of which is $15.9 \%$ lower than that of the existing formulation. In addition, the advantage of an integrated approach is obvious, when at first the maximum relative discrepancy of the measured parameters is minimized (second stage of identification), and then their sum (third stage). In this case, the value of the accuracy criterion decreases by $31.4 \%$, which indicates the effectiveness of this approach.

Table 1 presents the values of all control parameters (the value calculated on the mathematical model is given above, the value measured on the generating unit is given below). The value of criterion $(23,24)$ that characterizes the closeness between the calculated and measured values is given to the right of the parameter values. The closer is this value to zero, the lower is the relative discrepancy of the corresponding measurement. The parameters, whose measurements are absent (or were given approximately) or were excluded at one of the identification stages of the generating unit model are showed in the Table by filling. These measurements were excluded from further calculations. 
Calculation results, measurements of control parameters and values of criterion accuracy for three operation conditions of the studied generating unit model

\begin{tabular}{|c|c|c|c|c|c|c|c|}
\hline No & Parameter, measurement unit & 1 cond. & $k_{i}$ & 2 cond. & $k_{i}$ & 3 cond. & $k_{i}$ \\
\hline 1 & 2 & 3 & 4 & 5 & 6 & 5 & 6 \\
\hline 1 & Circulating water temperature before condenser & $\begin{array}{l}22,40 \\
22,05\end{array}$ & 1,044 & $\begin{array}{l}21,22 \\
21,65\end{array}$ & 1,280 & $\begin{array}{l}21,30 \\
21,25\end{array}$ & 0,137 \\
\hline 2 & Circulating water flow rate before condenser & $\begin{array}{l}10210 \\
10211\end{array}$ & 0,008 & $\begin{array}{l}10979 \\
10979\end{array}$ & 0,004 & $\begin{array}{l}10143 \\
10143\end{array}$ & 0,007 \\
\hline 3 & Feed water temperature before condenser & $\begin{array}{l}32,0 \\
32,0\end{array}$ & 0,000 & $\begin{array}{l}30,9 \\
30,9\end{array}$ & 0,000 & $\begin{array}{l}32,2 \\
32,2\end{array}$ & 0,000 \\
\hline 4 & Air temperature before primary tubular air heater & $\begin{array}{l}46,9 \\
46,1\end{array}$ & 0,273 & $\begin{array}{l}48,9 \\
48,7\end{array}$ & 0,086 & $\begin{array}{l}50,3 \\
49,5\end{array}$ & 0,283 \\
\hline 5 & Steam pressure after second turbine compartment & $\begin{array}{l}32,91 \\
32,91\end{array}$ & 0,006 & $\begin{array}{l}19,32 \\
19,32\end{array}$ & 0,031 & $\begin{array}{l}34,07 \\
34,07\end{array}$ & 0,005 \\
\hline 6 & Steam pressure before first turbine compartment & $\begin{array}{l}125,92 \\
128,16\end{array}$ & 2,684 & $\begin{array}{l}73,10 \\
70,44\end{array}$ & 3,192 & $\begin{array}{l}130,09 \\
132,75\end{array}$ & 3,192 \\
\hline 7 & $\begin{array}{l}\text { Steam pressure before second turbine } \\
\text { compartment }\end{array}$ & $\begin{array}{l}48,48 \\
46,39 \\
\end{array}$ & 9,663 & $\begin{array}{l}28,52 \\
26,99\end{array}$ & 7,063 & $\begin{array}{l}50,10 \\
49,50\end{array}$ & 2,772 \\
\hline 8 & Steam pressure before third turbine compartment & $\begin{array}{l}28,34 \\
28,59\end{array}$ & 1,862 & $\begin{array}{l}16,43 \\
16,00\end{array}$ & 3,192 & $\begin{array}{l}29,27 \\
29,69\end{array}$ & 3,185 \\
\hline 9 & Steam pressure before fourth turbine compartment & $\begin{array}{l}15,83 \\
15,82\end{array}$ & 0,152 & $\begin{array}{l}9,23 \\
9,17\end{array}$ & 0,699 & $\begin{array}{l}16,35 \\
16,41\end{array}$ & 0,690 \\
\hline 10 & Steam pressure before fifth turbine compartment & $\begin{array}{l}7,64 \\
9,25 \\
\end{array}$ & 48,18 & $\begin{array}{l}4,49 \\
4,64 \\
\end{array}$ & 4,483 & $\begin{array}{l}7,89 \\
9,60 \\
\end{array}$ & 51,35 \\
\hline 11 & Steam pressure before sixth turbine compartment & $\begin{array}{l}3,89 \\
3,89\end{array}$ & 0,249 & $\begin{array}{l}2,30 \\
2,30\end{array}$ & 0,010 & $\begin{array}{l}4,01 \\
4,01\end{array}$ & 0,133 \\
\hline 12 & $\begin{array}{l}\text { Steam pressure before seventh turbine } \\
\text { compartment }\end{array}$ & $\begin{array}{l}1,22 \\
1,20\end{array}$ & 1,862 & $\begin{array}{l}0,73 \\
0,70\end{array}$ & 2,741 & $\begin{array}{l}1,25 \\
1,50\end{array}$ & 25,39 \\
\hline 13 & Steam pressure before eighth turbine compartment & $\begin{array}{l}0,93 \\
0,91\end{array}$ & 2,856 & $\begin{array}{l}0,56 \\
0,58\end{array}$ & 3,196 & $\begin{array}{l}0,95 \\
0,93\end{array}$ & 3,196 \\
\hline 14 & Steam pressure before ninth turbine compartment & $\begin{array}{l}0,21 \\
0,17\end{array}$ & 12,28 & $\begin{array}{l}0,13 \\
0,10\end{array}$ & 9,252 & $\begin{array}{l}0,215 \\
0,160\end{array}$ & 16,63 \\
\hline 15 & Steam pressure before turbine condenser & $\begin{array}{l}0,065 \\
0,059\end{array}$ & 1,889 & $\begin{array}{l}0,044 \\
0,034\end{array}$ & 3,168 & $\begin{array}{l}0,064 \\
0,058\end{array}$ & 1,872 \\
\hline 16 & Steam pressure after first turbine compartment & $\begin{array}{l}412,1 \\
411,9\end{array}$ & 0,046 & $\begin{array}{l}401,2 \\
400,3\end{array}$ & 0,171 & $\begin{array}{l}412,6 \\
412,0\end{array}$ & 0,112 \\
\hline 17 & Steam pressure after second turbine compartment & $\begin{array}{l}359,2 \\
359,3\end{array}$ & 0,017 & $\begin{array}{l}351,5 \\
349,6\end{array}$ & 0,487 & $\begin{array}{l}359,3 \\
359,8\end{array}$ & 0,124 \\
\hline 18 & Steam pressure after third turbine compartment & $\begin{array}{l}483,3 \\
491,1\end{array}$ & 1,471 & $\begin{array}{l}480,6 \\
495,4\end{array}$ & 2,774 & $\begin{array}{l}487,6 \\
490,3\end{array}$ & 0,506 \\
\hline 19 & Steam pressure after fourth turbine compartment & $\begin{array}{l}382,1 \\
435,3\end{array}$ & 13,31 & $\begin{array}{l}383,4 \\
432,2\end{array}$ & 12,21 & $\begin{array}{l}386,2 \\
415,0 \\
\end{array}$ & 7,191 \\
\hline 20 & Steam pressure after fifth turbine compartment & $\begin{array}{l}298,7 \\
298,1\end{array}$ & 0,142 & $\begin{array}{l}302,5 \\
307,3\end{array}$ & 1,211 & $\begin{array}{l}302,0 \\
301,5\end{array}$ & 0,134 \\
\hline 21 & Steam pressure after sixth turbine compartment & $\begin{array}{l}177,1 \\
177,2 \\
\end{array}$ & 0,021 & $\begin{array}{l}183,8 \\
175,3\end{array}$ & 3,192 & $\begin{array}{l}179,1 \\
187,6\end{array}$ & 3,194 \\
\hline 22 & Steam pressure after seventh turbine compartment & $\begin{array}{l}156,7 \\
156,9\end{array}$ & 0,071 & $\begin{array}{l}166,1 \\
166,8\end{array}$ & 0,274 & $\begin{array}{l}157,5 \\
154,8\end{array}$ & 1,024 \\
\hline 23 & Steam pressure after eighth turbine compartment & $\begin{array}{l}61,0 \\
70,0\end{array}$ & 6,777 & $\begin{array}{l}81,4 \\
70,0\end{array}$ & 8,575 & $\begin{array}{l}61,3 \\
75,0\end{array}$ & 10,24 \\
\hline 24 & Steam pressure after ninth turbine compartment & $\begin{array}{l}37,3 \\
38,5\end{array}$ & 0,865 & $\begin{array}{l}30,3 \\
29,3\end{array}$ & 0,725 & $\begin{array}{l}36,9 \\
38,2 \\
\end{array}$ & 0,935 \\
\hline 25 & Circulating water temperature after condenser & $\begin{array}{l}29,6 \\
30,2\end{array}$ & 0,838 & $\begin{array}{l}25,4 \\
26,4\end{array}$ & 1,462 & $\begin{array}{l}28,8 \\
29,5\end{array}$ & 1,111 \\
\hline 26 & $\begin{array}{l}\text { Temperature of condensate-feed water mixture } \\
\text { after condenser }\end{array}$ & $\begin{array}{l}36,7 \\
38,8\end{array}$ & 3,175 & $\begin{array}{l}29,9 \\
29,6\end{array}$ & 0,416 & $\begin{array}{l}36,2 \\
38,2\end{array}$ & 3,056 \\
\hline 27 & $\begin{array}{l}\text { Turbine condensate temperature after first low- } \\
\text { pressure heater }\end{array}$ & $\begin{array}{l}55,7 \\
55,7\end{array}$ & 0,007 & $\begin{array}{l}47,7 \\
46,4\end{array}$ & 0,966 & $\begin{array}{l}51,3 \\
55,3\end{array}$ & 2,991 \\
\hline
\end{tabular}


Continuation of Table 1

\begin{tabular}{|c|c|c|c|c|c|c|c|}
\hline 1 & 2 & 3 & 4 & 5 & 6 & 5 & 6 \\
\hline 28 & $\begin{array}{l}\text { Turbine condensate temperature after second low- } \\
\text { pressure heater }\end{array}$ & $\begin{array}{l}96,7 \\
95,4\end{array}$ & 0,940 & $\begin{array}{l}83,3 \\
83,9\end{array}$ & 0,466 & $\begin{array}{l}97,2 \\
95,7\end{array}$ & 1,095 \\
\hline 29 & $\begin{array}{l}\text { Turbine condensate temperature after third low- } \\
\text { pressure heater }\end{array}$ & $\begin{array}{l}137,0 \\
139,4\end{array}$ & 1,775 & $\begin{array}{l}121,7 \\
122,5\end{array}$ & 0,625 & $\begin{array}{l}137,9 \\
139,9\end{array}$ & 1,534 \\
\hline 30 & Turbine condensate temperature after deaerator & $\begin{array}{l}165,2 \\
164,4\end{array}$ & 0,609 & $\begin{array}{l}144,3 \\
148,5\end{array}$ & 3,141 & $\begin{array}{l}166,5 \\
164,5\end{array}$ & 1,533 \\
\hline 31 & $\begin{array}{l}\text { Feed water temperature after fourth high-pressure } \\
\text { heater }\end{array}$ & $\begin{array}{l}198,9 \\
198,7\end{array}$ & 0,091 & $\begin{array}{l}175,1 \\
175,3 \\
\end{array}$ & 0,089 & $\begin{array}{l}200,4 \\
200,4\end{array}$ & 0,012 \\
\hline 32 & $\begin{array}{l}\text { Feed water temperature after fifth high-pressure } \\
\text { heater }\end{array}$ & $\begin{array}{l}236,3 \\
236,6\end{array}$ & 0,174 & $\begin{array}{l}208,7 \\
209,6\end{array}$ & 0,442 & $\begin{array}{l}238,1 \\
238,8\end{array}$ & 0,339 \\
\hline 33 & $\begin{array}{l}\text { Feed water temperature after sixth high-pressure } \\
\text { heater }\end{array}$ & $\begin{array}{l}259,8 \\
261,9\end{array}$ & 1,066 & $\begin{array}{l}229,5 \\
230,5\end{array}$ & 0,491 & $\begin{array}{l}261,7 \\
264,3\end{array}$ & 1,281 \\
\hline 34 & Electric power generated by turbine unit generator & $\begin{array}{l}227,10 \\
227,09\end{array}$ & 0,016 & $\begin{array}{l}124,97 \\
124,98\end{array}$ & 0,015 & $\begin{array}{l}235,74 \\
235,73\end{array}$ & 0,016 \\
\hline 35 & $\begin{array}{l}\text { Feed water temperature after boiler condensate } \\
\text { cooler }\end{array}$ & $\begin{array}{l}269,6 \\
269,6\end{array}$ & 0,007 & $\begin{array}{l}253,1 \\
249,0\end{array}$ & 2,034 & $\begin{array}{l}265,7 \\
263,9\end{array}$ & 0,918 \\
\hline 36 & $\begin{array}{l}\text { Steam temperature after high-pressure water } \\
\text { economizer }\end{array}$ & $\begin{array}{l}337,3 \\
332,7 \\
\end{array}$ & 1,722 & $\begin{array}{l}324,2 \\
332,7\end{array}$ & 3,196 & $\begin{array}{l}335,9 \\
327,4\end{array}$ & 3,193 \\
\hline 37 & Saturated steam pressure after boiler drum & $\begin{array}{l}166,95 \\
166,95\end{array}$ & 0,003 & $\begin{array}{l}144,12 \\
144,17\end{array}$ & 0,059 & $\begin{array}{l}174,83 \\
172,20\end{array}$ & 3,151 \\
\hline 38 & Steam temperature before radiant superheater & $\begin{array}{l}357,8 \\
358,2\end{array}$ & 0,126 & $\begin{array}{l}351,6 \\
360,1\end{array}$ & 2,547 & $\begin{array}{l}359,9 \\
358,1\end{array}$ & 0,537 \\
\hline 39 & Steam temperature after radiant superheater & $\begin{array}{l}413,2 \\
413,3\end{array}$ & 0,016 & $\begin{array}{l}441,0 \\
436,3\end{array}$ & 1,412 & $\begin{array}{l}407,3 \\
407,6\end{array}$ & 0,095 \\
\hline 40 & $\begin{array}{l}\text { Steam temperature after injection into primary } \\
\text { steam cooler }\end{array}$ & $\begin{array}{l}401,7 \\
399,2\end{array}$ & 0,628 & $\begin{array}{l}401,4 \\
401,5\end{array}$ & 0,015 & $\begin{array}{l}405,3 \\
405,6\end{array}$ & 0,087 \\
\hline 41 & $\begin{array}{l}\text { erature after first chain of middle } \\
\text { heater }\end{array}$ & $\begin{array}{l}444,8 \\
444,6\end{array}$ & 0,047 & $\begin{array}{l}453,7 \\
454,4\end{array}$ & 0,181 & $\begin{array}{l}446,7 \\
446,5\end{array}$ & 0,038 \\
\hline 42 & $\begin{array}{l}\text { perature after first chain of outer platen } \\
\mathrm{r}\end{array}$ & $\begin{array}{l}492,0 \\
494,3\end{array}$ & 0,587 & $\begin{array}{l}507,8 \\
506,6\end{array}$ & 0,307 & $\begin{array}{l}492,2 \\
492,8\end{array}$ & 0,144 \\
\hline 43 & erature after injection into secondary & $\begin{array}{l}484,2 \\
483,7\end{array}$ & 0,114 & $\begin{array}{l}493,7 \\
493,7\end{array}$ & 0,007 & $\begin{array}{l}488,9 \\
488,9\end{array}$ & 0,003 \\
\hline 44 & $\begin{array}{l}\text { rature after second chain of middle } \\
\text { heater }\end{array}$ & $\begin{array}{l}501,3 \\
501,3\end{array}$ & 0,011 & $\begin{array}{l}511,2 \\
512,5\end{array}$ & 0,320 & $\begin{array}{l}505,9 \\
504,9\end{array}$ & 0,241 \\
\hline 45 & after second chain of outer & $\begin{array}{l}518,0 \\
518,4\end{array}$ & 0,093 & $\begin{array}{l}528,8 \\
528,4\end{array}$ & 0,093 & $\begin{array}{l}522,4 \\
522,7\end{array}$ & 0,087 \\
\hline 46 & $\begin{array}{l}\text { Steam temperature after injection into tertiary } \\
\text { steam cooler }\end{array}$ & $\begin{array}{l}510,3 \\
509,5\end{array}$ & 0,203 & $\begin{array}{l}517,8 \\
519,4\end{array}$ & 0,402 & $\begin{array}{l}512,4 \\
512,1\end{array}$ & 0,076 \\
\hline 47 & Steam pressure after convection superheater & $\begin{array}{l}566,1 \\
566,3\end{array}$ & 0,044 & $\begin{array}{l}560,3 \\
566,9\end{array}$ & 1,649 & $\begin{array}{l}568,3 \\
566,8\end{array}$ & 0,364 \\
\hline 48 & Steam temperature after primary reheat & $\begin{array}{l}480,4 \\
481,3\end{array}$ & 0,214 & $\begin{array}{l}477,3 \\
485,8\end{array}$ & 2,118 & $\begin{array}{l}482,2 \\
476,8\end{array}$ & 1,345 \\
\hline 49 & $\begin{array}{l}\text { Steam temperature after injection into low- } \\
\text { pressure steam cooler }\end{array}$ & $\begin{array}{l}412,8 \\
410,6\end{array}$ & 0,548 & $\begin{array}{l}442,2 \\
441,7\end{array}$ & 0,113 & $\begin{array}{l}416,7 \\
417,4\end{array}$ & 0,164 \\
\hline 50 & Steam temperature after secondary reheat & $\begin{array}{l}513,9 \\
514,2\end{array}$ & 0,070 & $\begin{array}{l}519,0 \\
528,9\end{array}$ & 2,469 & $\begin{array}{l}518,3 \\
515,2\end{array}$ & 0,772 \\
\hline 51 & Steam temperature after tertiary reheat & $\begin{array}{l}573,7 \\
568,5\end{array}$ & 1,304 & $\begin{array}{l}567,0 \\
568,7\end{array}$ & 0,426 & $\begin{array}{l}578,7 \\
567,6\end{array}$ & 2,771 \\
\hline 52 & $\begin{array}{l}\text { Steam temperature after low-pressure water } \\
\text { economizer }\end{array}$ & $\begin{array}{l}109,5 \\
109,2\end{array}$ & 0,204 & $\begin{array}{c}97,1 \\
101,3\end{array}$ & 3,188 & $\begin{array}{l}110,0 \\
107,9\end{array}$ & 1,573 \\
\hline 53 & Gas temperature after primary tubular air heater & $\begin{array}{l}151,0 \\
149,3\end{array}$ & 0,538 & $\begin{array}{l}129,2 \\
139,9\end{array}$ & 3,189 & $\begin{array}{l}153,6 \\
146,1\end{array}$ & 2,271 \\
\hline 54 & Air temperature after secondary tubular air heater & $\begin{array}{l}320,5 \\
328,1\end{array}$ & 1,404 & $\begin{array}{l}287,4 \\
304,0\end{array}$ & 3,096 & $\begin{array}{l}321,0 \\
321,0\end{array}$ & 0,025 \\
\hline 55 & Primary steam flow rate after boiler & $\begin{array}{l}180,5 \\
184,2\end{array}$ & 2,963 & $\begin{array}{l}104,68 \\
101,96\end{array}$ & 2,174 & $\begin{array}{l}186,58 \\
186,61\end{array}$ & 0,027 \\
\hline 56 & $\begin{array}{l}\text { Flow rate of condensate-feed water mixture after } \\
\text { condenser }\end{array}$ & $\begin{array}{l}138,13 \\
154,07\end{array}$ & 15,94 & $\begin{array}{l}81,97 \\
77,74\end{array}$ & 4,233 & $\begin{array}{l}140,68 \\
161,17\end{array}$ & 20,49 \\
\hline
\end{tabular}


End of Table 1

\begin{tabular}{|c|c|c|c|c|c|c|c|}
\hline 1 & 2 & 3 & 4 & 5 & 6 & 5 & 6 \\
\hline 57 & $\begin{array}{l}\text { Gas temperature after high-pressure convection } \\
\text { superheater }\end{array}$ & $\begin{array}{l}752,1 \\
696,7\end{array}$ & 2,775 & $\begin{array}{l}656,2 \\
650,1\end{array}$ & 0,283 & $\begin{array}{l}759,7 \\
703,4\end{array}$ & 2,821 \\
\hline 58 & $\begin{array}{l}\text { Gas temperature after superheater of secondary } \\
\text { reheat }\end{array}$ & $\begin{array}{l}553,2 \\
458,5\end{array}$ & 5,686 & $\begin{array}{l}497,0 \\
447,1\end{array}$ & 2,999 & $\begin{array}{l}557,2 \\
457,1\end{array}$ & 6,009 \\
\hline 59 & $\begin{array}{l}\text { Gas temperature after superheater of primary } \\
\text { reheat }\end{array}$ & $\begin{array}{l}374,0 \\
339,6\end{array}$ & 2,586 & $\begin{array}{l}329,9 \\
313,3\end{array}$ & 1,251 & $\begin{array}{l}374,6 \\
332,4\end{array}$ & 3,173 \\
\hline 60 & $\begin{array}{l}\text { Gas temperature after high-pressure water } \\
\text { economizer }\end{array}$ & $\begin{array}{l}210,6 \\
207,0\end{array}$ & 0,375 & $\begin{array}{l}180,7 \\
192,5 \\
\end{array}$ & 1,168 & $\begin{array}{l}212,5 \\
202,4 \\
\end{array}$ & 1,022 \\
\hline \multicolumn{2}{|r|}{ Total relative deviation of measured parameters } & \multicolumn{2}{|c|}{38,93} & \multicolumn{2}{|c|}{63,50} & \multicolumn{2}{|c|}{56,59} \\
\hline
\end{tabular}

\section{Conclusions}

The paper describes an effective three-stage technique of mathematical model identification of complex thermal power equipment. The calculations show that the technique allows the more effective a) detection of gross errors in measurements of control parameters used for identification of mathematical model parameters of the studied equipment, b) assessment of correctness and amendment of errors in mathematical model construction and c) improvement of the accuracy of identification problem solution.

Besides, the paper describes criteria to assess the identification problem solution accuracy for both individual measurements of control parameters and the total discrepancy of all parameters in the considered operation conditions. The suggested technique also allows assessing an additional error due to imperfection of the standard calculation methods and assumptions in the mathematical model of the studied TPU besides the errors due to the accuracy of sensors used for equipment tests.

Also, in this paper, a new formulation of the optimization problem for the third stage of identification is presented, which makes it possible to more accurately tune mathematical models of heat power equipment for real modes of operation.

The effective three-stage technique of mathematical model identification was tried on the detailed mathematical model of the 225 MW present-day generating unit that was constructed by the author. The paper presents results of the problem solution on identification of mathematical model parameters of the generating unit.

\section{References}

1. Tarazanov I.G. Results of the work of the coal industry in Russia for January-December 2018 // Coal, 2019. - No. 3. - pp. 64 - 79. DOI: http://dx.doi.org/10.18796/0041-5790-2019-3-64-79 (in Russian)

2. Coal industry in Russia [site]. [2019]. URL: https://wtcmoscow.ru/services/internationalpartnership/analitycs/ugolnaya-otrasl-rossii/ (in Russian)
3. Statistical Review of World Energy: [site]. [2019]. URL: http://www.bp.com/en/global/corporate/energyeconomics/statistical-review-of-world-energy.html

4. Ghosh T.K., Prelas M.A. Energy Resources and Systems: Volume 1: Fundamentals and Non-Renewable Resources. -Springer Science + Business Media B.V. 2009. - pp. $159-279$.

5. Bruce G. Miller. Coal Energy Systems // Elsevier Academic Press, 2005. - P. 526.

6. Kler A.M., Dekanova N.P., Korneeva ZR, Mikheev A.V. Mathematical modeling and optimization of CHP operation modes // New technologies and scientific developments in power engineering (operation, repair, non-traditional energy sources): Theses of reports. - Novosibirsk: Union of Scientific and Engineering Societies of the USSR. Novosibirsk Regional Administration of the All-Union Scientific and Technical Society of Power Engineers and Electrical Engineers, 1994. - issue 2. - pp.27-29. (in Russian)

7. Kler A.M., Dekanova N.P., Skripkin S.K. and other. Mathematical modeling and optimization in the problems of operational control of thermal power plants. - Novosibirsk: Science. Sib. enterprise RAS, 1997. - P. 120. (in Russian)

8. Kler A.M., Dekanova N.P., Skripkin S.K. Mathematical and software support for the algorithm for correcting the measured parameters for calculating technical and economic indicators at CHP / Novosibirsk: Science. Sib. published. firm RAS, 1997. - P. 120. (in Russian)

9. Kler A.M., Dekanova N.P., Stepanova E.L. Optimization of operating parameters and composition of operating equipment of large energy sources // Izv. RAS. Energy, 2004. - No. 6. - pp. 43-52. (in Russian)

10. Kler A.M., Dekanova N.P., Korneeva ZR, Mikheev A.V. Optimization of modes in the operational management of CHP // Energy of Russia in the transition period: problems and scientific foundations of development and management. / Ed. A.P. Merenkov. Novosibirsk: Science. Sib. published. firm, 1996. P.141-146. (in Russian)

11. Kler A.M., Dekanova N.P., Mikheev A.V. Numerical methods for diagnostics of TPP equipment // Thermophysics and aeromechanics, 2000. - V.7. - №3. pp. 443-450. (in Russian)

12. Kler A.M., Maksimov A.S., Stepanova E.L. Methods for constructing high-speed mathematical 
models of turbines for problems of operational optimization of operating modes of a CHP plant // Energosystems, power plants and their units: collection of articles. scientific. works / ed. acad. RAS Nakoryakova V.E. - Novosibirsk: Publishing house of NSTU, 2005. - Issue 9 - pp. 85-99. (in Russian)

13. Kler A.M., Maximov A.S., Stepanova E.L. et al: Optimizing the Operating Modes of Cogeneration Stations Taking Actual State of Main Equipment into Account, Thermal Engineering, 2009, Vol. 56, No. 6, pp. 500-505.

14. Claire A.M., Maksimov A.S., Stepanova E.L., Zharkov P.V. Rapid assessment of the state of the main equipment of TPPs // Electric power stations, 2011. - No. 4. - P. 2-6. (in Russian)

15. Kler, A.M., Maximov, A.S., Stepanova, E.L. High-speed mathematical models of cogeneration steam turbines: optimization of operation in heat and power plants, Thermophysics and Aeromechanics, 2006, Vol. 13, No.1, pp. 143-150.

16. Manuel Chica, José Barranquero, Tomasz Kajdanowicz. Multimodal optimization: An effective framework for model calibration // Information Sciences. - Volume 375, 1 January 2017, Pages 79-97. https://doi.org/10.1016/j.ins.2016.09.048.

17. Karim Salahshoor, Majid Soleimani Khoshro, Mojtaba Kordestani. Fault detection and diagnosis of an industrial steam turbine using a distributed configuration of adaptive neuro-fuzzy inference systems // Simulation Modelling Practice and Theory. - Volume 19, Issue 5, May 2011, Pages 1280-1293.

18. Xiaolong Jiang, Pei Liu, Zheng Li. Data reconciliation for steam turbine on-line performance monitoring // Applied Thermal Engineering. - Volume 70, Issue 1, 5 September 2014, Pages 122-130. https://doi.org/10.1016/j.applthermaleng.2014.05.007.

19. Alekseyuk V.E., Maksimov A.S., Safronov P.G. An improved technique for identifying mathematical models of heat power equipment. Irkutsk State Technical University Bulletin. - 2019. -№23 (3). - pp. 503-515. DOI: $10.21285 / 1814-3520-2019-3-503-515$. (in Russian)

20. Kler A.M., Alekseyuk V.E. An effective method of tuning mathematical models of heat and power equipment to its actual state. Bulletin of the Perm National Research Polytechnic University. Electrical engineering, information technology, control systems. 2019. - No. 31. - S. 136-159. (in Russian)

21. V.E. Alexeyuk, "An Improved Technique For Identification Of Mathematical Models Of Thermal Power Equipment," Energy Systems Research, Vol. 1, No. 3, pp. 53-60, 2018, http://dx.doi.org/10.25729/esr.2018.03.0007.

22. Kler A.M., Alekseyuk V.E. Increasing the accuracy of identifying the parameters of mathematical models of the existing heat and power equipment // Scientific Bulletin of NSTU. - 2019. - No. 3 (76). - pp. 57-76. - DOI: 10.17212 / 1814-1196-2019-3-57-76. (in Russian)

23. Aleksandr Kler, Vitalii Alekseiuk and Aleksei Maksimov, «An improved technique for identification of mathematical model parameters of thermal power equipment and assessment of its performance»,
International Conference of Young Scientists "Energy Systems Research 2019”, Vol. 114, 2019, DOI: https://doi.org/10.1051/e3sconf/201911406009.

24. Kobzar A.I. Applied mathematical statistics. For engineers and scientists. - 2nd corrected edition. - M.: FIZMATLIT, 2012. - 816 p. (in Russian)

25. Alexeyuk V.E. Improvement of the technique for identification of mathematical models based on the test results of a condensing turbine unit. Systems Research in Energy. Proceedings of Young Scholars at Melentiev Energy Systems Institute, Siberian Branch, Russian Academy of Sciences. Irkutsk: ISEM SO RAN, 2017, issue 47, pp. 42 - 55. (in Russian)

26. Alexeyuk V.E., Maximov A.S. Identification of the mathematical model of a condensing turbine unit based on test results / Proceedings of the All-Russian Scientific and Practical Conference with international participation "Improvement of energy production and utilization efficiency under Siberian conditions", Irkutsk: Izd-vo IrNITU, pp. 284 - 288, April 24 - 271, 2017. (in Russian)

27. Kler A.M., Mai V.A., Skripkin S.K.: A system for computer-based creation of static and dynamic mathematical models of thermal power plants, Proceedings, $2^{\text {nd }}$ International forum, Expert systems and computer simulation in energy engineering, Erlangen, Germany, March 17-20, 1992, pp. 22-4-1 - 22-4-3. 